\title{
Early Lactate Clearance Rate is an Indicator of Outcome in Severe Sepsis and Septic Shock
}

\author{
Sultana $\mathrm{R}^{\mathrm{a}^{*}}$, Hamid $\mathrm{T}^{\mathrm{b}}$, Ahsan ASMA ${ }^{\mathrm{c}}$, Fatema $\mathrm{K}^{\mathrm{d}}$, Ahmed Fe, Saha DK ${ }^{\mathrm{f}}$, Saha $\mathrm{M}^{\mathrm{g}}$, \\ Nazneen $\mathrm{S}^{\mathrm{h}}$, Islam $\mathrm{A}^{\mathrm{i}}$
}

\begin{abstract}
Background: Lactate clearance is an important marker of global tissue hypoxia and might be used as an indicator of outcome in patients with severe sepsis and septic shock. This study was done to see the association between lactate clearance with the outcome of the patients of severe sepsis and septic shock among the patients who were admitted in the Department of Critical Care Medicine of BIRDEM General Hospital.

Methods: This observational study was done in the Department of Critical Care Medicine, BIRDEM General Hospital from August 2015 to July 2016. At zero hour (during admission), first sample of serum lactate was sent and second sample after 6 hours of resuscitation for calculation of lactate clearance rate. Patients having lactate clearance e" $10 \%$ were classified as high lactate clearance (HLC) and $<10 \%$ were low lactate clearance (LLC).

Results: Total 186 patients (male 96, female 90, mean age 63.07 14.17 years) with severe sepsis (80) and septic shock (106) were enrolled. Diabetes mellitus (DM) was the most common co morbidity (76.9\%) and predominant diagnosis was pneumonia (90.3\%). Among patients with septic shock, 51.9\% (55/106) had LLC and 48.1\% (51/106) had HLC. Among patients with severe sepsis, 28.8\% (23/80) had LLC and 71.2\% (57/80) had HLC. Among 57 patients of HLC group of severe sepsis, $73.6 \%(n=42)$ were survivors and $26.3 \%(n=15)$ were non-survivor and 23 patients of LLC group of severe sepsis, $26.09 \%(n=6)$ were survivors and $73.91 \%$ $(n=17)$ were-non survivors $(p=<0.001)$. Among 51 patients of HLC group of septic shock, $78.43 \%(n=40)$ were survivors and $21.57 \%(n=11)$ were non-survivors and 55 patients of LLC group of septic shock, 29.09\% $(n=16)$ were survivors and $70.91 \%(n=39)$ were non-survivors $(p=<0.001)$.
\end{abstract}

Conclusion: Patients with HLC after 6 hours of management had better outcome than LLC.

Key Words: Lactate clearance rate, septic shock, severe sepsis, outcome.

(BIRDEM Med J 2018; 8(3): 223-228)

\section{Author Information}

a. *Dr. Rozina Sultana, Registrar, Department of Critical Care Medicine ,BIRDEM General Hospital.

b. *Dr. Tarikul Hamid, Medical Officer, Department Dept. of Critical Care Medicine, BIRDEM General Hospital.

c. Prof. A.S.M. Areef Ahsan, Head, Department of Critical Care Medicine, BIRDEM General Hospital.

d. Dr. Kaniz Fatema, Associate Professor, Department of Critical Care Medicine, BIRDEM General Hospital.

e. Dr. Fatema Ahmed, Associate Professor, Department of Critical Care Medicine, BIRDEM General Hospital.

f. Dr. Debasish Kumar Saha, Junior Consultant, Department of Critical Care Medicine, BIRDEM General Hospital.

g. Dr. Madhurima Saha, Registrar, Department of Critical Care Medicine, BIRDEM General Hospital.

h. Dr. Suraiya Nazneen, Registrar, Department of Critical Care Medicine, BIRDEM General Hospital.

i. Dr. Ariful Islam, Medical Officer, Department of Critical Care Medicine, BIRDEM General Hospital.

Address of Correspondence: Dr. Rozina Sultana, FCPS (Medicine), MD (Critical Care Medicine), Registrar, Department of Critical Care Medicine, BIRDEM General Hospital, Dhaka, Bangladesh. Cell no: 01712028599, Email: rpmcliza@gmail.com

* First two authors should be considered as a first authors

Received: December 24, 2017

Accepted: June 30, 2018

\section{Introduction}

The incidence of severe sepsis and the number of sepsis related death is increasing. Sepsis is now the $10^{\text {th }}$ most common cause of death in the united states. ${ }^{1}$ The definition of severe sepsis and septic shock has been formulated since early 1990s and has been accepted worldwide. ${ }^{2}$ So, when sepsis is associated with hypo perfusion or single organ dysfunction, it becomes severe sepsis. When hypoperfusion in severe sepsis persists in spite of adequate fluid resuscitation and requiring vasopressors, it is called septic shock. ${ }^{2}$ The cornerstone for management of severe sepsis is the early diagnosis, administration of appropriate antibiotic and early hemodynamic resuscitation. There is a need to test the prognostic value of factors that could be used for guiding therapy after the initial resuscitation. Only a few laboratory tests for markers of sepsis are currently available. Serum lactate level can help in determining prognosis and to risk stratify patients with severe sepsis 
and septic shock. In healthy individuals, there is a continuous cycle of lactate production and metabolism, which ensures that blood lactate concentrations are normally low. Elevated blood lactate concentrations above the accepted normal reference range (absolute hyperlactataemia) are common and associated with increased in hospital mortality in the critically ill patients. Their usefulness in identifying critically ill patients at higher risk of death has led to the adoption of lactate measurement in most blood gas analyzers and the frequent measurement of lactate in the critically ill patients. ${ }^{3}$ Serum lactate is a component of prognostic models in severe sepsis and septic shock and concentration is increased in these patients. Numerous studies have established the use of lactate as a diagnostic, therapeutic and prognostic marker of global tissue hypoxia in circulatory shock. ${ }^{4-8}$ The serum lactate concentrations measured in almost all patients with severe sepsis raised at admission and were higher in patients who had the worse outcomes such as higher APACHE (Acute Physiology and Chronic Health Evaluation) II score. ${ }^{9}$

The sensitivity and specificity of single lactate concentrations as a marker of tissue hypoperfusion have been debated. However serial measurement or lactate clearance over time may be better prognosticators of organ failure and mortality. ${ }^{10}$ Early lactate clearance seems to be an important determinant of survival in patients with severe sepsis.

Lactate clearance rate, derived from calculating the changes in lactate concentration from 2 blood sample specimens drawn at different times, potentially represents a more accessible method to assess tissue oxygen delivery. ${ }^{11,12}$ The lactate clearance was defined by the equation

$\left[\left(\right.\right.$ Lactate $_{\text {initial }}$ " Lactate delayed $/$ Lactate $\left._{\text {initial }}\right] \times 100 \%$, for which lactate initial was the measurement at the start of the resuscitation and lactate delayed was another measurement after a minimum of 2 hours after resuscitation was initiated. Lactate clearance at least $10 \%$ in resuscitation goal in severe sepsis and septic shock. ${ }^{13,14}$ This study was done to see the association between lactate clearance with the outcome of the patients of severe sepsis and septic shock among the critically ill patients who are admitted in the Department of Critical Care Medicine of BIRDEM General Hospital.

\section{Methods}

This prospective observational study was done in the Department of Critical Care Medicine (CCM) of BIRDEM General Hospital, Dhaka, Bangladesh from $1^{\text {st }}$ August 2015 to $31^{\text {st }}$ July 2016. All adult patients admitted in CCM Department with the features of severe sepsis and septic shock, were initially entitled for the study purpose. Patient with myocardial infarction, left ventricular failure, history of acute alcohol ingestion or poisoning, seizure, pregnancy, malignancy or requiring immediate surgery were excluded. Total patients ware 186. All consecutive patients with severe sepsis and septic shock according to Surviving Sepsis Campaign (SSC) guidelines fulfilling the selection criteria were included in the study. Informed written consent was taken from patients' first degree relatives. After inclusion, that is at zero hour of development of severe sepsis or septic shock, blood sample for serum lactate level was sent to hospital laboratory. After 6 hours second sample was measured at biochemistry laboratory by analyzer named Ortho Clinical Vitros 250 chemistry system of GMI where normal reference value of lactate is 3.6 to $18 \mathrm{mg} / \mathrm{dl}$.

Then Lactate clearance rate was calculated by following formula:

\section{Lactate clearance rate}

$\left[\left(\right.\right.$ Lactate $_{\text {Hour 0 }}$ "Lactate $\left.{ }_{\text {Hour 6 }}\right) /$ Lactate $\left._{\text {Hour 0 }}\right] \times 100 \%$

According to lactate clearance rate, all patients of severe sepsis and septic shock were divided into two group, that is low lactate clearance (LLC) and high lactate clearance (HLC) group.

Patients having lactate clearance e" $10 \%$ were classified as HLC group and $<10 \%$ were LLC group.

Twenty one days was taken as follow up period for all patients in this study.Outcome were measured by mortality. Those who were discharged or transferred were classified as survivors and those who died were categorized as non survivors. Follow up of survivors was done by phone up to 21 days.

Those who were neither discharged nor died during the study period were classified as survivors. Patient's resuscitation and management were done according to the standard protocol of the Department of Critical Care Medicine of BIRDEM General Hospital. Data were recorded in pre-tested structured data sheet and analyzed 
by using Statistical Package for Social Sciences (SPSS) software (version 18).

\section{Results}

During the study period, a total 186 patients fulfilled the criteria of sepsis and septic shock. Among 186 patients, $51.6 \%$ of the patients were male and $48.4 \%$ were female, mean age was $63.07 \pm 14.17$ years (Table I). Baseline characteristics were shown in Table II. Different types of co-morbidities were shown in Figure 1 and diagnoses were shown in Figure 2. In this study among the total 106 (57\%) septic shock patients, 51.9\% $(\mathrm{n}=55)$ had LLC and $48.1 \%(\mathrm{n}=51)$ had HLC, among $80(43 \%)$ severe sepsis patients, $28.8 \%(\mathrm{n}=23)$ had LLC and $71.3 \%(\mathrm{n}=57)$ patients had HLC. (Table III). In this study among 57 patients of HLC group of severe sepsis, $73.6 \%(\mathrm{n}=42)$ were survivors and $26.3 \%(\mathrm{n}=15)$ were non survivor and 23 patients of LLC, $26.09 \%(\mathrm{n}=6)$ were survivors and $73.91 \%(\mathrm{n}=17)$ were non survivors. (Table IV). Among 51 patients of HLC group of septic shock, $78.43 \%(\mathrm{n}=40)$ were survivors and $21.57 \%$ $(\mathrm{n}=11)$ were non survivors and 55 patients of LLC group of septic shock, $29.09 \%(\mathrm{n}=16)$ were survivors and $70.91 \%(n=39)$ were non survivors. (Table V). Validity test result of lactate clearance for outcome prediction in severe sepsis group was shown in Table VI and by ROC (Receiver Operating Characteristics) curve in Figure 3 and in septic shock group in Table VII and Figure 4 respectively.

Table I Distribution of patients by their age $(\mathrm{n}=186)$

\begin{tabular}{lcc}
\hline Age (years) & Frequency $(\mathrm{n})$ & Percentage $(\%)$ \\
\hline d" 40 & 19 & 10.2 \\
$41-50$ & 15 & 8.1 \\
$51-60$ & 37 & 19.9 \\
$61-70$ & 63 & 33.9 \\
$71-80$ & 35 & 18.8 \\
e" 80 & 17 & 9.1 \\
Total & 186 & 100.00 \\
\hline
\end{tabular}

Mean $\pm \mathrm{SD}=63.07 \pm 14.17$; range $=24$ - 92 years

\begin{tabular}{|c|c|c|}
\hline Variables & Mean \pm SD & $\begin{array}{c}\text { Range } \\
\text { (Min-max) }\end{array}$ \\
\hline Systolic BP (mmHg) & $84.6 \pm 20.2$ & $33.0-150.0$ \\
\hline Diastolic BP (mmHg) & $52.7 \pm 13.9$ & $26.0-100.0$ \\
\hline Mean Arterial Pressure & $48.6 \pm 12.5$ & $21.2-90.0$ \\
\hline $\mathrm{Hb} \%(\mathrm{gm} / \mathrm{dl})$ & $10.8 \pm 1.9$ & $3.3-16.6$ \\
\hline Total WBC Count & $24.2 \pm 7.5$ & $2.38-47.4$ \\
\hline Platelet count & $184401 \pm 100003$ & $7000-599000$ \\
\hline S. Creatinine (mg/dl) & $4.2 \pm 3.4$ & $0.7-19.2$ \\
\hline Initial lactate level (mg/dl) & $37.5 \pm 18.3$ & $12-112$ \\
\hline $\begin{array}{l}\text { Use of mechanical } \\
\text { ventilation } \mathrm{n}(\%)\end{array}$ & $112(60.2)$ & \\
\hline Duration of ICU stay & $5.26 \pm 3.15$ & $0.33-20.00$ \\
\hline
\end{tabular}

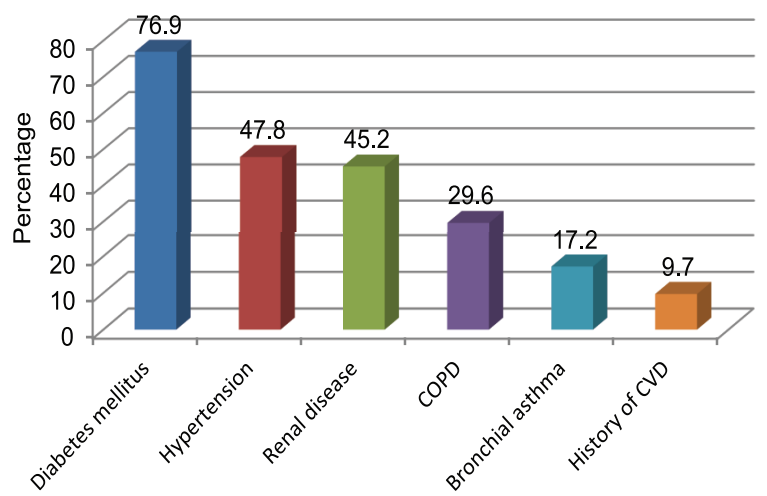

Figure 1 Bar chart of associated co-morbidities of the patients

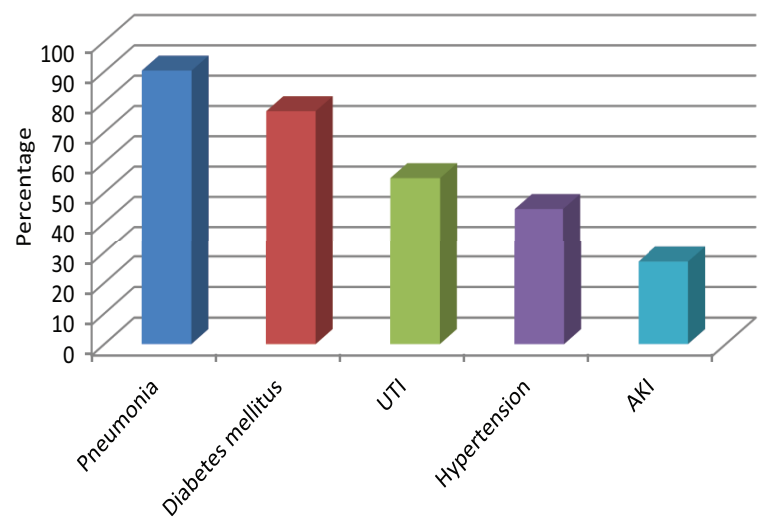

Figure 2 Bar chart of diagnosis of the patients 
Table III Proportion of LLC and HLC in severe sepsis and septic shock

\begin{tabular}{lccc}
\hline & \multicolumn{2}{c}{ Group } & Total \\
& LLC & HLC & \\
\hline Septic Shock & $55(51.9)$ & $51(48.1)$ & $106(57.0)$ \\
Severe Sepsis & $23(28.8)$ & $57(71.3)$ & $80(43.0)$ \\
\hline
\end{tabular}

Table IV Comparison of lactate clearance between survivor and non-survivors groups of Severe sepsis patients

Variable Group Total p-value
Survivors Non-survivors

\begin{tabular}{llll}
\hline HLC & $42(73.6 \%)$ & $15(26.3 \%)$ & $57(71.3)<0.001$
\end{tabular}

LLC $\quad 6(26.09 \%) \quad 17(73.91 \%) \quad 23(28.8)$

\begin{tabular}{llll}
\hline Total & 48 & 32 & $80(100.0)$ \\
\hline
\end{tabular}

Chi-square test was done to measure the level of significance.

Table V Comparison of lactate clearance between survivor and non-survivors groups of Septic shock patients

\begin{tabular}{|c|c|c|c|c|}
\hline$\overline{\text { Varial }}$ & $\mathrm{Gr}$ & oup & Total & $\overline{p \text {-value }}$ \\
\hline & Survivors & Non-survivors & & \\
\hline HLC & $40(78.43 \%)$ & $11(21.57 \%)$ & $51(48.1)$ & $<0.001$ \\
\hline LLC & $16(29.09 \%)$ & 39 (70.91\%) & 55 (51.9) & \\
\hline Total & 98 & 50 & $106(100.0)$ & \\
\hline
\end{tabular}

Chi-square test was done to measure the level of significance.

Table VI The validity test results of lactate clearance in prediction of outcome (severe sepsis group)

\begin{tabular}{lcc}
\hline Parameter & $\begin{array}{c}\text { Estimated } \\
\text { Value }(\%)\end{array}$ & $\begin{array}{c}95 \% \mathrm{CI} \\
(\mathrm{min}-\max )\end{array}$ \\
\hline Sensitivity & 87.5 & $78.4-94.2$ \\
Specificity & 53.1 & $39.4-63.2$ \\
Positive predictive value & 73.7 & $66.0-79.3$ \\
Negative predictive value & 73.9 & $54.8-87.9$ \\
Accuracy & 73.8 & $62.8-81.8$ \\
\hline
\end{tabular}

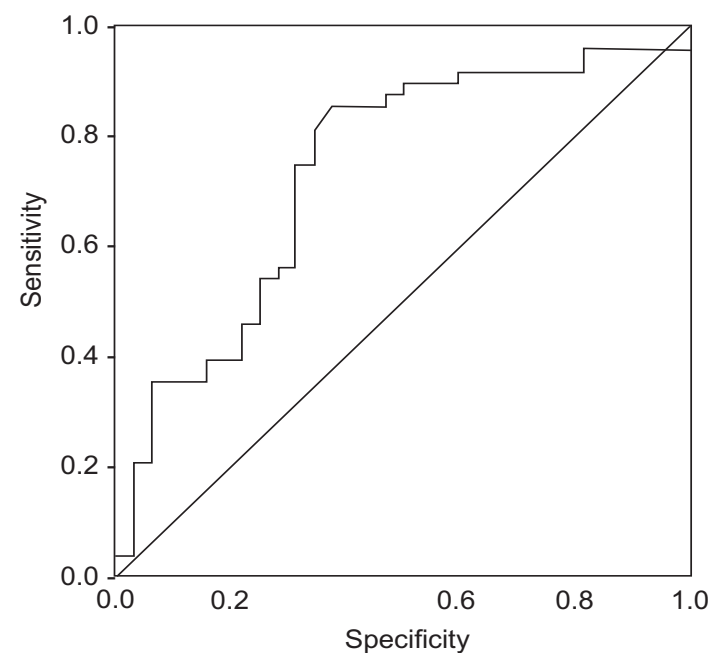

Diagonal segments are produced by ties

Figure 3 ROC curve of lactate clearance in prediction of outcome (severe sepsis group) [AUC $=0.736]$

Table VII The Validity test results of lactate clearance in prediction of outcome (septic shock group)

\begin{tabular}{lcc}
\hline Parameter & $\begin{array}{c}\text { Estimated } \\
\text { Value (\%) }\end{array}$ & $\begin{array}{c}95 \% \mathrm{CI} \\
(\mathrm{min}-\max )\end{array}$ \\
\hline Sensitivity & 71.4 & $62.0-79.0$ \\
Specificity & 78.0 & $67.4-86.4$ \\
Positive predictive value & 78.4 & $68.0-86.7$ \\
Negative predictive value & 70.9 & $61.3-78.6$ \\
Accuracy & 74.5 & $64.5-82.5$ \\
\hline
\end{tabular}

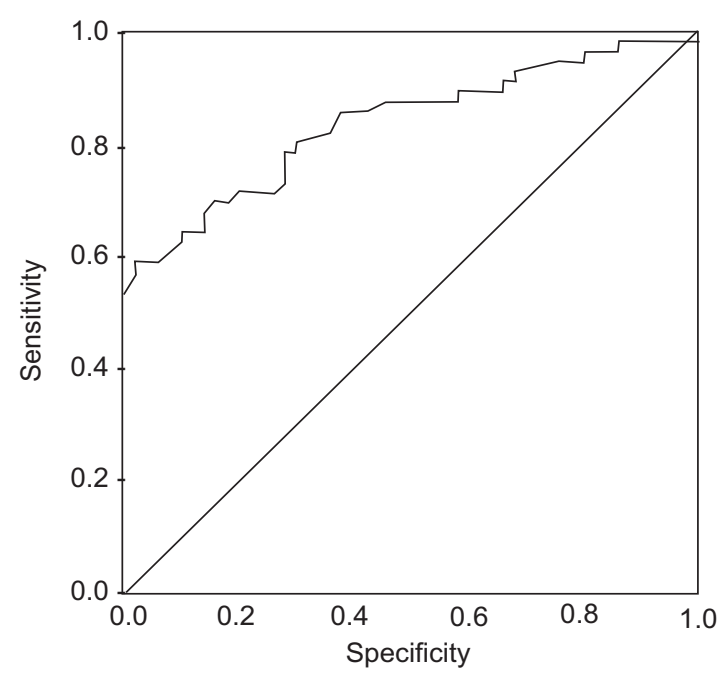

Diagonal segments are produced by ties

Figure 4 ROC curve of lactate clearance in prediction of outcome (septic shock groups) [AUC $=0.837]$ 


\section{Discussion}

Severe sepsis and septic shock are very common in ICU settings. A total 186 of patients fulfilled the criteria of sepsis and septic shock during the study period. The mean and SD of age in this study were $63.07 \pm 14.17$ years. Commonest age range was 61-70 (33.9\%) indicating elderly are more prone to developed severe sepsis and septic shock.

In an epidemiologic studiy of severe sepsis are difficult to compare, not only because their results are influenced by their date of implementation and the type of ICU analyzed, but also because severe sepsis is a highly heterogeneous condition. ${ }^{15}$ Another study compared non-severe sepsis patients with severe sepsis patients and found that severe sepsis patients were significantly older and had male predominance. ${ }^{16}$ In this study $51.6 \%$ $(\mathrm{n}=96)$ were male \& 48.4\% $(\mathrm{n}=90)$ were female. A study describe the epidemiology of severe sepsis in the United States: analysis of inci-dence, outcome, and associated costs of care noticed that certain co -morbid conditions such as diabetes mellitus, chronic liver diseases, HIV and cancer have been suggested to increase the risk of developing sepsis. ${ }^{15}$

In this study diabetes mellitus was the most common (76.9\%) co-morbidity and the predominant diagnosis were pneumonia (90.3\%), DM (76.3\%), HTN (44.6\%), AKI (26.9\%), UTI (8.1\%). Another study conduct epidemiology of sepsis in Germany and revealed respiratory and renal dysfunction were the most frequent organ dysfunctions ( $52.0 \%$ and $42.2 \%$, respectively) and the most frequent sites of infection were the respiratory tract $(62.9 \%)$ and the abdomen $(25.3 \%) .{ }^{17}$ In a study, it was found that the predominant admission diagnoses were pneumonia and urosepsis, with $52.3 \%$ patients presenting in septic shock. ${ }^{11}$

In our study among 186 patients, 57\% ( $\mathrm{n}=106)$ were septic shock and $43 \%(n=80)$ patients present with severe sepsis. In a study found that among 111 patients, 31 patients had low lactate clearance and 80 patients had high lactate clearance. Among low lactate clearance group 29\% patients was diagnosed as severe sepsis, 71\% was diagnosed as septic shock. In high lactate clearance group 55\% patients was diagnosed as severe sepsis and $45 \%$ was diagnosed as septic shock. There were significantly more severe sepsis patients with high lactate clearance compared with patients with low lactate clearance $(p=.01)$. They showed that the high-clearance group had a $52.0 \%$ relatively lower in-hospital mortality rate compared with the low clearance group ( $p=.001)$, and this mortality difference was similarly observed up to 60 days. In severe sepsis patients, those with high lactate clearance had significantly lower mortality rate than patients with low clearance $(p=.03)$. There were significantly fewer septic shock patients with high lactate clearance; however, there was a trend toward decreased mortality rate in these patients compared with the septic shock patients with low lactate clearance $(p=.01$ and .06 , respectively). ${ }^{11}$

In this study among 57 patients of HLC group of severe sepsis, $73.6 \%(n=42)$ were survivors and $26.3 \%(n=15)$ were non survivor and 23 patients of LLC, $26.09 \%(n=6)$ were survivors and $73.91 \%(n=17)$ were non survivors. Among 51 patients of HLC group of septic shock, $78.43 \%(n=40)$ were survivors and $21.57 \%(n=11)$ were non survivors and 55 patients of LLC group of septic shock, 29.09\% $(n=16)$ were survivors and 70.91\% $(n=39)$ were non survivors. The present study extends the concept of lactate normalization during early therapeutic intervention. Our findings suggest that lactate clearance, as defined by the percentage of lactate cleared over the first 6 hours period of disease presentation, is an independent variable associated with decreased mortality rate. During resuscitation, a lactate clearance of $>10 \%$ from its baseline value in as brief a period as 6 hours is achievable. Initial serial lactate measurements in the presence of SIRS alert the clinician to the severity of illness and may be associated with outcome.

\section{Limitations}

As the sample size was small, the findings derived from study cannot be generalized to reference population. This study was carried out in an adult Intensive Care Unit (ICU). So pediatric group of population was not included in this study and this study was conducted in a tertiary care hospital where most of the patient populations were diabetic and having pre existing multiple co -morbidities.

\section{Conclusion}

Lactate clearance in the most proximal presentation of severe sepsis and septic shock is associated with improved morbidity and mortality rates. This is consistent with current efforts that emphasize the importance of identifying and treating tissue 
hypoperfusion during the first 6 hours of resuscitation. Further clinical trials are needed to conclusively establish lactate clearance as a resuscitation end point and an outcome measure to be targeted during the most proximal phases of severe sepsis and septic shock. Late diagnosis and multi organ dysfunction increases the mortality. Early management strategy associated with improved outcome is sustained over time and is demonstrated across a wide number of countries and settings. We need guidelines for early identification, management \& prevention of sepsis for resource limited country like Bangladesh. In particular, we believe that this study highlights a variety of epidemiologic and health services research issues that remain poorly understood, including optimal delivery of care for vulnerable and elderly populations. Future studies should include a larger number of patients and ICU to better understand and treat patients with severe sepsis and septic shock.

Conflict of interest: Nothing to declare.

\section{References}

1. Jafar, M., Ehsan, B., Monaver, A. A. Serum lactate is a useful predictor of death in severe sepsis and septic shock. Reviews in Clinical Medicine 2014; 1: 97-103.

2. Levy MM, Fink MP, Marshall JC, Abraham E, Angus D, Cook D, et al. $2001 \mathrm{SCCM} / \mathrm{ESICIM} / \mathrm{ACCP} / \mathrm{ATI} /$ SIS international Sepsis definitions Conference. Crit. Care Med 2003; 31: 1250-6.

3. Alister, D.N., Moritoki, E.,Ville, P., Rinaldo, B.,Craig, F., Graeme, H., et al: 2Relative hyper lactatemia and hospital mortality in critically ill patients : a retrospective multi- centre study. Critical Care; 2010; 14:R 25

4. Weil, M.H., Afifi, A.A. Experimental and clinical studies on lactate and pyruvate as indicators of the severity of acute circulatory failure (shock). Circulation 1970; 41:989-1001

5. Vitek, V., Cowley, R.A. Blood lactate in the prognosis of various forms of shock. Ann Surg 1971; 173:308-313.

6. Moomey, C.B., Melton, Sherry M., Croce, Martin, A., Fabian et al. Prognostic value of blood lactate, base deficit, and oxygen-derived variables in an LD50 model of penetrating trauma. Crit Care Med 1999; 27:154-161.
7. Cowan, B.N., Burns, H.J., Boyle, P., Ledingham. The relative prognostic value of lactate and hemodynamic measurement in early shock. Anaesthesia 1984; 39:750-755.

8. James, J.H., Luchette, F.A., McCarter, F.D., Fischer, J. E. Lactate is an unreliable indicator of tissue hypoxia in injury or sepsis. Lancet 1999; 354:505-508.

9. Lee, S.M., Kim, S.E., Kim, E.B., Jeong H.J.,Son Y.K., An. W.S. Lactate Clearnce and Vasopressor seem to be Predictors for Mortality in severe sepsis Patients with Lactic acidosis supplementing Sodium Bicarbonate : A retrospective analysis. PLOS One 2015; 10(12).

10. Nguyen HB, Kuan WS, Batech M, Shrikhande P, Mahadevan $\mathrm{M}, \mathrm{Li} \mathrm{CH}$, et al. Outcome effectiveness of the severe sepsis resuscitation bundle with addition of lactate clearance as a bundle item: a multi-national evaluation. Crit Care 2011; 15(5): R229.

11. Nguyen, H.B., Rivers, E.P., Knoblich, B.P., Jacobseen, G., Muzzin, A., Julie, A.et al. Early lactate clearance is associated with improved outcome in severe sepsis and septic shock. Crit Care Med 2004; 32:1637-42

12. Shapiro, N.I., Fisher, C., Donnino, M., Cataldo, L., Tang, A., Trzeciak, S.,et al. The feasibility and accuracy of point-ofcare lactate measurement in emergency department patients with suspected infection. J Emerg Med 2010; 39: 89-94.

13. Rivers, E., Nguyen, B., Havstad, S., Ressler, J., Muzzin, A., Knoblich, B., et al. Early Goal-Directed Therapy Collaborative Group. Early goal-directed therapy in the treatment of severe sepsis and septic shock. N Engl J Med 2001 8;345:1368-77.

14. Puskarich, M.A., Trzeciak, S., Shapiro, N.I., Arnold, R.C., Heffner, A.C., Kline, J.A., et al. Emergency Medicine Shock Research Network (EMSHOCKNET). Prognostic value and agreement of achieving lactate clearance or central venous oxygen saturation goals during early sepsis resuscitation. Acad Emerg Med 2012;19:252-58.

15. Angus, D.C., Walter, T., Linde- Zwirble, Lidicker, J., Clermont, G., Carcillo J, et al. Epidemiology of severe sepsis in the united states: Analysis of incidence, outcome, and associated costs of care. Critical Care Medicine 2001; 29: $1303-10$.

16. Guidet, B., Aegerter, P., Gauzit, R., Meshaka, P., Dreyfuss, D. Incidence and impact of organ dysfunctions associated with sepsis. Chest 2005;127:942-51.

17. Engel, C., Brunkhorst, F. M., Bone, H., Brunkhorst, R., Gerlach, H., Grond, S., et al., Epidemiology of sepsis in Germany: results from a national prospective multicenter study. Intensive Care Med 2007; 33:606-18. 